\title{
Detection of Nitric Oxide Production in Cell Cultures by Luciferin-Luciferase Chemiluminescence
}

By Yakov Y. Woldman ${ }^{a, e}$, Tim D. Eubank ${ }^{c}$, Andrew J. Mock ${ }^{b}$, Natalia C. Stevens ${ }^{b}$, Saradhadevi Varadhara ${ }^{c}$, Jenifer Turco ${ }^{b}$, Mikhail A. Gavrilin ${ }^{c}$, Bruce R. Branchini ${ }^{d}$, Valery V. Khramtsov ${ }^{c}$

${ }^{a}$ Department of Chemistry, Valdosta State University, Valdosta, GA 31698

${ }^{b}$ Department of Biology, Valdosta State University, Valdosta, GA 31698

${ }^{c}$ Davis Heart \& Lung Research Institute, The Ohio State University, Columbus, OH 43210

${ }^{d}$ Department of Chemistry, Connecticut College, New London, CT 06320

${ }^{e}$ To whom correspondence should be addressed, ywoldman@valdosta.edu, (229)-333-5452 


\section{ABSTRACT}

A chemiluminescent method is proposed for quantitation of NO generation in cell cultures. The method is based on activation of soluble guanylyl cyclase by NO. The product of the guanylyl cyclase reaction, pyrophosphate, is converted to ATP by ATP sulfurylase and ATP is detected in a luciferin-luciferase system. The method has been applied to the measurement of NO generated by activated murine macrophages (RAW 264.7) and bovine aortic endothelial cells. For macrophages activated by lipopolysaccharide and $\gamma$-interferon, the rate of NO production is about $100 \mathrm{amol} /($ cell-min). The rate was confirmed by the measurements of nitrite, the product of $\mathrm{NO}$ oxidation. For endothelial cells, the basal rate of $\mathrm{NO}$ generation is $5 \mathrm{amol} /(\mathrm{cell} \cdot \mathrm{min})$; the rate approximately doubles upon activation by bradykinin, $\mathrm{Ca}^{2+}$ ionophore $\mathrm{A} 23187$ or mechanical stress. For both types of cells the measured rate of $\mathrm{NO}$ generation is strongly affected by inhibitors of $\mathrm{NO}$ synthase. The sensitivity of the method is about $50 \mathrm{pM} / \mathrm{min}$, allowing the registration of $\mathrm{NO}$ generated by $10^{2}-10^{4}$ cells. The enzyme-linked chemiluminescent method is two orders of magnitude more sensitive than fluorescent detection using 4-amino-5methylamino-2',7'-difluorofluorescein (DAF-FM).

Keywords: nitric oxide; guanylyl cyclase; pyrophosphate; macrophages; endothelial cells; thermostable luciferase 


\section{Introduction}

Nitric oxide (NO) plays an important role as a signaling molecule in regulation of smooth muscle tone [1], neurotransmission [2] and immune response [3, 4]. Due to this universal role, its generation is crucial for the symptoms and pathology of numerous diseases [5-10], including AIDS, sickle-cell disease, diabetes and pulmonary hypertension. Depending on its level, NO can either promote or inhibit tumor progression [11] and plays role in ischemia/reperfusion injury [12]. These facts illustrate the importance of a quantitative assay for nitric oxide in biological systems at physiologically and pathologically relevant levels.

Methods currently in use for biological systems including chemiluminescent reaction with ozone, electrochemical detection, fluorescent detection and EPR approaches are summarized in reviews [13, 14]. Enzyme-linked NO detection suggested in our and other works [15-17] is based on the changing of catalytic activity of an enzyme in the presence of NO. The concept, first suggested in our publication [17], is outlined on Scheme 1. Here the target enzyme is the natural target of nitric oxide, soluble guanylyl cyclase (sGC), NO serves as a catalytic molecule rather than a direct analyte and detection is based on luciferin-luciferase chemiluminescence. This method was demonstrated in simple NO-generating systems, such as NO donors (NONOates) and inducible NO synthase (iNOS). The aim of the current study is to extend the method to quantification of NO generation in cell culture.

As it follows from the scheme, NO-activated soluble guanylyl cyclase (sGC) produces pyrophosphate $\left(\mathrm{PP}_{\mathrm{i}}\right)$, the latter being immediately converted to ATP by ATP-sulfurylase. Thus, at a constant NO concentration, ATP is constantly produced, generating linear increase in ATPdependent luminescence. It means the slope of the luminescence vs. time curve provides the measure of the steady-state NO concentration in solution, reflecting the rate of NO generation.

In current work, enzymatic assay was applied to two cell types: murine macrophages (RAW 264.7 and primary murine bone marrow macrophages) and bovine aortic endothelial cells 
(BAEC). It should be noted that unlike methods employing fluorescent dyes that penetrate inside the cell, the assay detects extracellular NO. The level of available NO outside the producing cell is physiologically relevant when intracellularly produced nitric oxide is consumed by intracellularly produced superoxide, making less nitric oxide available for intercellular communication [18].

\title{
Materials and Methods
}

\author{
MATERIALS
}

Chemicals (catalog number in parentheses): ATP (A7699), sodium pyrophosphate (S6422), DTPA (D6518), D-luciferin (L6152), adenosine-5'-phosphosulfate sodium salt (A5508, APS), Trizma base (T1503), DTT (43817), 2,3-diaminonaphthalene (D2757), E. coli lipopolysaccharide (L3129, LPS), bradykinin acetate (B3259), calcium ionophore A23187 (C7522), EGTA (E4378) were from Sigma-Aldrich. HEPES (H9897), arginine (BP370), GTP (R0461, 100 mM aqueous solution), Coomassie Plus (Bradford) Assay Kit (23236) were from Fisher Scientific. Magnesium chloride (194698) was from MP Biomedicals. $N^{G}$-monomethyl- L- arginine (80200, NMMA), $N^{G}$ nitro- L- arginine methyl ester (80210, NAME), DETA NONOate (82120), 7-nitroindazole (81340) were from Cayman Chemical. Murine interferon- $\gamma$ (315-05) was from PeproTech.

Enzymes. Guanylyl cyclase (ALX-202-039) was from Alexis Biochemicals; ATP sulfurylase (M0394L) was from New England Biolabs; inorganic pyrophosphatase (11891), firefly luciferase (L9506), superoxide dismutase (S9697), BSA (A7906) were from Sigma-Aldrich.

Engineered Luciferases. Promega Ultra-Glo luciferase was prepared from luciferin detection reagent (CYP1A1 assay) as described in Supplement. The thermostable Green Luciferase (GRTS) was expressed in E. coli (BL21(DE3)) as GST fusion protein and purified following the corresponding protocol [19]. 
NO donors. A stock solution of DETA NONOate was prepared in $0.01 \mathrm{M} \mathrm{NaOH}$, and its concentration was determined using $\varepsilon=7640 \mathrm{M}^{-1} \mathrm{~cm}^{-1}$ at $252 \mathrm{~nm}$. The stock solution was diluted with water to necessary concentration prior to use.

Cells. Murine macrophages (RAW264.7) were grown in DMEM with 10\% FBS and were stimulated with INF- $\gamma(100$ units $/ \mathrm{mL}, 18 \mathrm{~h})$ and then LPS (20 ng/mL, $4 \mathrm{~h}$ ). The other details of cell maintenance are given in Supplement.

\section{Buffers.}

MP-HEPES (for macrophages): $0.137 \mathrm{M} \mathrm{NaCl}, 2.7 \mathrm{mM} \mathrm{KCl}, 30 \mathrm{mM}$ HEPES, $1 \mathrm{mM}$ arginine, 2 $\mathrm{mM}$ glutamine, $20 \mathrm{mM}$ glucose, $\mathrm{pH} 7.4$ at $25^{\circ} \mathrm{C}$.

Hi HEPES (for endothelial cells): $0.18 \mathrm{M} \mathrm{HEPES} \mathrm{(titrated} \mathrm{by} \mathrm{NaOH}$ ), $5.4 \mathrm{mM} \mathrm{KCl,} 1 \mathrm{mM} \mathrm{MgCl}$, $10 \mathrm{mM}$ glucose, $2 \mathrm{mM}$ glutamine, $1 \mathrm{mM}$ arginine, $\mathrm{pH} 7.55$ at $25^{\circ} \mathrm{C}$. Where indicated, this buffer contained $1.3 \mathrm{mM} \mathrm{CaCl}_{2}$.

INSTRUMENTATION

Luminescence and fluorescence measurements were conducted at $37^{\circ} \mathrm{C}$ using plate reader Victor $^{3}$ (Perkin-Elmer), with black or white clear bottom 96-well plates (Nunclon, 137101 and 165306). Nitrite assays were run on spectrofluorometer (Hitachi), excitation $365 \mathrm{~nm}$, emission $404 \mathrm{~nm}$, bandwidth $2 \mathrm{~nm}$.

\section{METHODS}

Composition of the reaction mixture for NO measurements. Unless otherwise stated, the reaction mixture for luminescence measurements $(200 \mu \mathrm{L})$ contained: $1 \mathrm{mM} \mathrm{MgCl}, 1 \mathrm{mM} \mathrm{DTE}$, $50 \mu \mathrm{M}$ DTPA, $0.1 \mathrm{mg} / \mathrm{mL}$ BSA, $25 \mu \mathrm{M}$ D-luciferin, $2 \mu \mathrm{g}$ luciferase, $20 \mathrm{mU}$ PPase, $25 \mathrm{ng}$ guanylyl 
cyclase, $10 \mathrm{mU}$ sulfurylase, $50 \mathrm{U}$ superoxide dismutase, $10 \mu \mathrm{M}$ APS and $0.1 \mathrm{mM}$ GTP in HEPES-based buffer.

NO measurements. Stock solutions of low molecular weight and protein components were prepared and kept on ice. Low molecular weight components solution contained $\mathrm{MgCl}_{2}$, DTE, luciferin, APS and GTP. Protein components solution contained DTPA, PPase, SOD, luciferase and BSA. Concentrations of the components were chosen in such a way that addition of small aliquots gave the final concentrations shown above. Before the measurements, cells were rinsed twice and the medium was replaced with warm HEPES-based medium. Low molecular weight $(6.2 \mu \mathrm{L})$ and protein $(8.0 \mu \mathrm{L})$ components of the assay mixture were added to the wells and left for temperature stabilization and residual pyrophosphate hydrolysis (2 min). Then, sulfurylase was added and luminescence without sGC was recorded. Next, $2 \mu \mathrm{L}$ of sGC were added and the luminescence kinetics was recorded for 3 minutes. For endothelial cells, stimulus (bradykinin or $\mathrm{Ca}^{2+}$ ionophore) was added after sulfurylase, followed by $90 \mathrm{~s}$ delay and addition of sGC + EGTA; then, luminescence kinetics was recorded. In all the experiments luminescence integration time was $1 \mathrm{~s}$.

Shaking was done directly in the Victor ${ }^{3}$ luminometer prior to reading with the following parameters: double orbital path, diameter $0.2 \mathrm{~mm}$, slow speed $(10 \mathrm{~mm} / \mathrm{s})$, duration $5 \mathrm{~s}$.

Nitrite measurements. Cells were rinsed twice with MP-HEPES medium and incubated for a specified time at $37^{\circ} \mathrm{C}$. Then, $150 \mu \mathrm{L}$ of the media was taken to separate plate for nitrite analysis, which proceeded by adding $1.5 \mu \mathrm{L}$ of $1 \mathrm{mM}$ diaminonaphthalene and $0.63 \mu \mathrm{L}$ of 12.1 $\mathrm{M} \mathrm{HCl}$ to each well. Samples were incubated for $30 \mathrm{~min}$ in the dark and then $3.3 \mu \mathrm{L}$ of $3 \mathrm{M} \mathrm{NaOH}$ was added. Sodium nitrite in the same buffer was used as a standard. Nitrite was determined by fluorescence with excitation at $365 \mathrm{~nm}$ and emission at $404 \mathrm{~nm}$.

\section{CALCULATIONS}


The primary data are the kinetics of luminescence change. The rate of the luminescence change, calculated as a slope of the kinetics, depends on the NO generation rate and can be used for NO quantitation in the sample. As luminescence intensity is measured in counts per second (cps), the rate of luminescence change would be measured in "counts per second per second" $\left(\mathrm{cps}^{2}\right)$. The method was calibrated with known concentrations of the NO donor, DETA NONOate, using the protocol described above in NO measurements. DETA NONOate was added to the assay mixture in the wells without cells or with non - NO generating cells (quiescent macrophages). Typical calibration (Figure 1, Supplement) shows the dependence of the luminescence increase rate on concentration of NO donor to be approximately linear at low concentrations of the donor. The rate of NO generation was determined from the change of DETA-NONOate absorbance at $252 \mathrm{~nm}$. It was $0.80 \mathrm{nM} / \mathrm{min}$ of $\mathrm{NO}$ per $1 \mu \mathrm{M}$ of donor concentration under the conditions of cellular assays. This value is close to the one reported in literature [20]. The calibration curve was produced for every series of experiments.

\section{STATISTICAL ANALYSIS}

All values presented in this paper are expressed as the mean \pm standard error of the mean; the same are error bars on the graphs. One-way Student $t$ test was used to calculate statistical significance.

\section{Results}

\section{Choice of luciferase for the cellular assay}

Initial experiments were conducted with wild-type firefly luciferase. However, its instability at $37^{\circ} \mathrm{C}$ made quantitative measurements difficult. Two thermostable engineered luciferases: Ultra-Glo (Promega) and GR-TS [19] were tested along with wild type firefly luciferase. As GRTS luciferase showed the least variation of luminescence over time, it was chosen for further experiments (see Supplement for details). 


\section{Choice of the buffer}

Phosphate-containing buffers cannot be used in our assay, as phosphate interferes with pyrophosphate detection. Therefore, HEPES buffers of physiological osmolarity were used. To test cell tolerance, the cells were rinsed and incubated in the buffer for 10 minutes (the time required for the measurement), then medium was replaced with standard growth medium and the cells were examined under the microscope. We found neither morphological changes nor changes in the number of cells after such treatment.

\section{Detection of nitric oxide in cellular systems}

The method was applied to measurement of NO production by RAW 264.7 cells, bone marrowderived murine macrophages and BAEC. The primary kinetics traces shown in Fig. $1 \mathrm{~A}$ correspond to $1.0 \cdot 10^{3}$ RAW cells in a 96-well plate. The cell number-dependent NO generation rate for the same cells (Fig. 1B) was calculated using calibration with NO donor DETA NONOate; the rate of NO production was $(96 \pm 11) \mathrm{amol} /(\mathrm{min} \cdot \mathrm{cell})$. To confirm this quantitation, we measured the final product of NO oxidation, nitrite, with the same cells (Fig. 1C). Due to lower sensitivity, these measurements require a higher number of cells and longer time for nitrite accumulation. However, the calculated nitrite production rate, $(78 \pm 8) \mathrm{amol} /(\mathrm{min} \cdot \mathrm{cell})$ was in agreement with the number calculated from NO measurements.

To confirm the specificity of the observed luminescence increase, the cells were treated with inhibitors of NO-synthase, L-NAME and 7-nitroindazole (Fig. 1D, E). Another inhibitor of NOsynthase, L-NMMA, produces similar results (Supplement Fig. 3).

Analogous results were obtained with primary murine bone marrow-derived macrophages. Rates of NO generation, $80-140 \mathrm{amol} /(\mathrm{min} \cdot \mathrm{cell})$ were recorded for cells stimulated by the scheme described in Materials and Methods, while quiescent cells exhibit negligible NO production, $0-0.2 \mathrm{amol} /(\mathrm{min} \cdot \mathrm{cell})$. 
The other cellular system, BAEC, requires $\mathrm{Ca}^{2+}$ in the buffer, and this ion inhibits sGC [21]. To overcome the problem, cells were incubated with all the components of the assay, then $\mathrm{Ca}^{2+}$ chelator (EGTA) along with sGC were added and luminescence kinetics was recorded. The presence of $1 \mathrm{mM} \mathrm{Ca}^{2+}$ does not affect the luminescence without $\mathrm{SGC}$ and chelated $\mathrm{Ca}^{2+}$ does not affect the activity of sGC [21]. When the effect of bradykinin or $\mathrm{Ca}^{2+}$ ionophore (A23187) on NO production was examined, the 90 s delay was introduced before adding sGC + EGTA. The results of the experiments are shown in Fig. 2. In these experiments the luminescence increase for both stimulated (A23187 or bradykinin) and non-stimulated cells is fully attributed to NO generation, as is proven by negligible slope of the kinetics without sGC (Fig. 2A, dotted line) and by inhibition with L-NAME (Fig. 2B, C). Endothelial cells sensitivity to mechanical stimulation is a cornerstone of vascular physiology, so it would be important to observe this sensitivity using chemiluminescent method. Special equipment is required to produce quantitatively defined shear stress; however, ordinary shaking necessarily involves shear stress and can be used for qualitative observations. Indeed, the cells responded to shaking in a manner dependent on cell number and the response was abolished by adding an eNOS inhibitor or by omitting SGC (Fig. 2D). The negative value for the control in the absence of sGC reflects a slightly negative slope of the kinetic curve explained by a slow decay of luciferase-dependent luminescence (Supplement Fig. 2). The data show that, unlike quiescent macrophages, endothelial cells maintain a basal level of NO production, which increases in response to different stimuli and is strongly inhibited by L-NAME, a specific eNOS inhibitor. Based on calibration with NO donor, the rate of NO production was $4.8 \pm 1.8 \mathrm{amol} /(\mathrm{cell} \cdot \mathrm{min}$ ) for basal and $7.4 \pm 1.8,11 \pm 2.5$ and $9.4 \pm 0.5$ amol/(cell-min) for A23187, bradykinin and mechanically-stimulated cells, respectively.

\section{Comparison of sensitivity of chemiluminescent and fluorescent detection of NO}

Fig. 3 shows the results of the experiment where either RAW cells $\left(1.0 \cdot 10^{4}\right.$ cells per well) or synthetic NO donor were used as a source of nitric oxide, with detection by either $10 \mu \mathrm{M}$ DAF- 
FM (Fig. 3 A, B) or by the chemiluminescent assay (Fig. 3 C, D). As can be seen, barely visible increase in fluorescence was observed with $5 \mu \mathrm{M}$ of DETA NONOate after 120 minutes, while chemiluminescent detection generates an excellent kinetic curve with $1.25 \mu \mathrm{M}$ of $\mathrm{NO}$ donor in 100 seconds or less. For either source of NO, the chemiluminescent method appears to be two orders of magnitude more sensitive.

\section{Discussion}

\section{Background luminescence}

The suggested method is based on the activation of sGC by nitric oxide. It leads to exceptional sensitivity, as one molecule of SGC, being activated by one molecule of NO, can produce many molecules of pyrophosphate, which is detected after conversion to ATP. Obviously, lower background is desirable for the improved sensitivity: to this end, cells were treated with pyrophosphatase before the measurements. However, as the concentration of NO translates to the rate of ATP production with proportional rate of the luminescence increase, the level of the background luminescence is not critically important, giving an additional advantage to the method.

\section{Sensitivity and limitations}

To achieve maximal sensitivity, most of NO should be bound to SGC, meaning concentration of the enzyme to be higher than $K_{D}$ and NO concentration. However, these conditions could be impractical due to high cost of purified guanylyl cyclase. As seen from Fig. 2D, $0.8 \mathrm{nM}$ concentration of SGC used in our assays allows for the measurement of $\mathrm{NO}$ generation rates as low as $50 \mathrm{pM} / \mathrm{min}$. This corresponds to detection of $\mathrm{NO}$ generated by $10^{2}-10^{3}$ cells like murine macrophages or $(1-5) \cdot 10^{3}$ cells of endothelial lineage. The method is more applicable for 
relatively low NO generation rates in order to avoid saturation of SGC (Fig. 1, Supplement). The other limitation is the involvement of ATP and $\mathrm{PP}_{\mathrm{i}}$ in the detection, so method cannot be applied to ATP-effusing cells, neither can it be used to study the effect of extracellular ATP on cell physiology. However, physiological effects, including change in NO production, were observed at extracellular ATP concentrations of 10-300 $\mu \mathrm{M}$ [22-25], while maximal concentration of ATP generated in our experiments did not exceed $100 \mathrm{nM}$, even for the most intensely NOgenerating cells. That means the detection method does not directly interfere with cell physiology.

\section{Basal generation of NO by BAEC; no generation by quiescent macrophages}

The presented data show that basal NO generation by endothelial cells is substantial and increases about 2-3 times upon stimulation. This corresponds to the role of eNOS, maintaining vascular tone, which has to rapidly change in response to physiological stimuli (shear stress, bradykinin). The fact that the basal and stimulated activities are both eNOS-mediated is supported by the strong inhibition by the specific eNOS inhibitor, L-NAME. For macrophages the expression of iNOS is triggered by external stimuli (bacterial LPS, cytokines) and in quiescent cells, NO-generating activity is undetectable.

\section{Numerical comparison with data produced by other methods}

Quantitative data concerning NO production by different cell types are scarce. The data for stimulated murine macrophages (ANA-1 cell line) demonstrate the rates of about 100 amol/(cell-min) [26], in agreement with our quantitation. Other work reports a yield of 7 amol/(cell-min) [27]; the difference may be explained by dissimilarity in cell lines (J774) and stimulation scheme. NO production by macrophages can be compared with the total oxygen consumption by the same type of cells, which is about $500 \mathrm{amol} /(\mathrm{cell} \cdot \mathrm{min})$ [28]. Evidently, the substantial part of consumed oxygen (about $40 \%$ ) in these cells is spent on NO production. For 
endothelial cells, studies report the values from 0.6 to $3 \mathrm{amol} /(\mathrm{cell} \cdot \mathrm{min})$ and bradykininstimulated increase of 3-6 times over the basal rate $[23,29,30]$. Our results agree with those data produced by different methods.

\section{Shear stress quantitation}

Calculation of shear stress originating from orbital shaking of cell cultures is widely discussed in literature [31-33]. The reason for this is universal accessibility of orbital shakers, while the devices specifically intended for providing defined shear stress are still uncommon. The calculations performed for standard 6-well culture plate [32] showed great non-uniformity of shear stress both over the orbiting cycle and across the well. However, the average shear stress magnitude over the bottom of the well falls fairly close to the value predicted by analytical solution for the simpler model of infinite plate orbiting beneath a liquid layer of large height:

$$
\tau=R_{g} \Omega^{3 / 2} \sqrt{\rho \mu}
$$

where $\tau$ is shear stress, $R_{g}$ is orbiting radius, $\Omega$ is angular orbital speed, $\rho$ is density and $\mu$ is dynamic viscosity.

The average shear stress value of $0.1 \mathrm{~Pa}$ was calculated using equation (1) for our settings. Shear stress of this magnitude, though lower than in physiological conditions for human arteries (0.5 Pa, [34]), caused visible elevation in NO production measured by NO electrode [29]. It should be noted, that the value of $0.1 \mathrm{~Pa}$ presents an estimate of the average shear stress; the peak values could be an order of magnitude higher.

In summary, the chemiluminescent method for extracellular measurement of NO production was successfully applied to different cell types. The method allows to measure NO generated by $10^{2}$ $-10^{4}$ cells. The method is fast (2-3 minutes per measurement), does not require pre-loading cells with dye, and well-suited for high-throughput screening. Appropriate instrumentation (CCD- 
based luminometer with automatic injectors) will allow kinetics in all wells to be recorded simultaneously providing information for drug screening and other applications.

\section{Acknowledgements}

YYW acknowledges the support of Valdosta State University Faculty Research Grants (2012, 2014) and thanks Dr. Jesse Spencer (Valdosta State University) for help with manuscript preparation.

\section{Abbreviations}

APS, adenosine-5'-phosphosulfate; BAEC, bovine aortic endothelial cells; BSA, bovine serum albumin; cGMP, guanosine $3^{\prime}, 5^{\prime}$-cyclic monophosphate; cps, counts per second; $\mathrm{cps}^{2}$, counts per second per second; DETA NONOate, diethylenetriamine NONOate; DMEM, Dulbecco's modified Eagle's medium; DTE, 1,4-dithioerythritol; DTPA, diethylenetriamine-pentaacetic acid; DTT, dithiothreitol; EGTA, ethylene glycol-bis(2-aminoethylether)- $N, N, N^{\prime}, N^{\prime}$-tetraacetic acid; eNOS, endothelial nitric oxide synthase; FBS, fetal bovine serum; INF- $\gamma$, murine interferon $\gamma$; iNOS, inducible nitric oxide synthase; LPS, E. coli lipopolysaccharide; M-CSF, macrophage colony-stimulating factor; L(D)-NAME, $N^{G}$-nitro-L(D)-arginine methyl ester; NMMA, $\mathrm{N}^{G}$-monomethyl- L- arginine; $\mathrm{PP}_{\mathrm{i}}$, inorganic pyrophosphate; PPase, inorganic pyrophosphatase; sGC, soluble guanylyl cyclase; SOD, superoxide dismutase.

\section{References}

[1] L.J. Ignarro, G.M. Buga, K.S. Wood, R.E. Byrns, G. Chaudhuri, Endothelium-derived relaxing factor produced and released from artery and vein is nitric oxide, Proc. Natl. Acad. Sci. U. S. A., 84 (1987) 92659269. 
[2] J. Garthwaite, S.L. Charles, R. Chess-Williams, Endothelium-derived relaxing factor release on activation of NMDA receptors suggests role as intercellular messenger in the brain, Nature, 336 (1988) 385-388.

[3] P. Tripathi, Nitric oxide and immune response, Indian J. Biochem. Biophys., 44 (2007) 310-319.

[4] J. MacMicking, Q.W. Xie, C. Nathan, Nitric oxide and macrophage function, Annu. Rev. Immunol., 15 (1997) 323-350.

[5] M.I. Bukrinsky, H.S. Nottet, H. Schmidtmayerova, L. Dubrovsky, C.R. Flanagan, M.E. Mullins, S.A. Lipton, H.E. Gendelman, Regulation of nitric oxide synthase activity in human immunodeficiency virus type 1 (HIV-1)-infected monocytes: implications for HIV-associated neurological disease, J. Exp. Med., 181 (1995) 735-745.

[6] C.D. Reiter, X. Wang, J.E. Tanus-Santos, N. Hogg, R.O. Cannon, 3rd, A.N. Schechter, M.T. Gladwin, Cell-free hemoglobin limits nitric oxide bioavailability in sickle-cell disease, Nat. Med., 8 (2002) 13831389.

[7] N.A. Hartell, H.E. Archer, C.J. Bailey, Insulin-stimulated endothelial nitric oxide release is calcium independent and mediated via protein kinase B, Biochem. Pharmacol., 69 (2005) 781-790.

[8] F. Hoffmeyer, M. Raulf-Heimsoth, R. Merget, T. Bruning, [EBC: a new matrix for assessment of airway and lung inflammation. Current aspects of environmental and occupational medicine], Pneumologie, 63 (2009) 426-432.

[9] H.M. van Eijk, Y.C. Luiking, N.E. Deutz, Methods using stable isotopes to measure nitric oxide (NO) synthesis in the L-arginine/NO pathway in health and disease, J Chromatogr B Analyt Technol Biomed Life Sci, 851 (2007) 172-185.

[10] C.R. Morris, M.T. Gladwin, G.J. Kato, Nitric oxide and arginine dysregulation: a novel pathway to pulmonary hypertension in hemolytic disorders, Curr Mol Med, 8 (2008) 620-632. 
[11] D. Fukumura, S. Kashiwagi, R.K. Jain, The role of nitric oxide in tumour progression, Nat Rev Cancer, 6 (2006) 521-534.

[12] J.L. Zweier, P. Wang, A. Samouilov, P. Kuppusamy, Enzyme-independent formation of nitric oxide in biological tissues, Nat. Med., 1 (1995) 804-809.

[13] N.S. Bryan, M.B. Grisham, Methods to detect nitric oxide and its metabolites in biological samples, Free Radic. Biol. Med., 43 (2007) 645-657.

[14] H. Hong, J. Sun, W. Cai, Multimodality imaging of nitric oxide and nitric oxide synthases, Free Radic. Biol. Med., 47 (2009) 684-698.

[15] S.M. Marques, J.C.G. Esteves da Silva, A nitric oxide quantitative assay by a glyceraldehyde 3phosphate dehydrogenase/phosphoglycerate kinase/firefly luciferase optimized coupled bioluminescent assay, Analytical Methods, 6 (2014) 3741-3750.

[16] Y. Sano, M. Seki, S. Abe, S. Suzuki, H. Arakawa, Bioluminescent Assay for Nitric Oxide Utilizing the Biological Enzyme Activity of Soluble Guanylate Cyclase, Anal. Lett., 44 (2011) 2834-2840.

[17] Y.Y. Woldman, J. Sun, J.L. Zweier, V.V. Khramtsov, Direct chemiluminescence detection of nitric oxide in aqueous solutions using the natural nitric oxide target soluble guanylyl cyclase, Free Radic. Biol. Med., 47 (2009) 1339-1345.

[18] C. Kimura, M. Oike, T. Koyama, Y. Ito, Impairment of endothelial nitric oxide production by acute glucose overload, Am J Physiol Endocrinol Metab, 280 (2001) E171-178.

[19] B.R. Branchini, D.M. Ablamsky, M.H. Murtiashaw, L. Uzasci, H. Fraga, T.L. Southworth, Thermostable red and green light-producing firefly luciferase mutants for bioluminescent reporter applications, Anal. Biochem., 361 (2007) 253-262.

[20] L.K. Keefer, R.W. Nims, K.M. Davies, D.A. Wink, "NONOates" (1-substituted diazen-1-ium-1,2diolates) as nitric oxide donors: convenient nitric oxide dosage forms, Methods Enzymol., 268 (1996) 281-293. 
[21] L. Serfass, H.S. Carr, L.M. Aschenbrenner, J.N. Burstyn, Calcium ion downregulates soluble guanylyl cyclase activity: evidence for a two-metal ion catalytic mechanism, Arch. Biochem. Biophys., 387 (2001) 47-56.

[22] T. D'Amico Oblak, P. Root, D.M. Spence, Fluorescence monitoring of ATP-stimulated, endotheliumderived nitric oxide production in channels of a poly(dimethylsiloxane)-based microfluidic device, Anal. Chem., 78 (2006) 3193-3197.

[23] D.H. Kotsis, D.M. Spence, Detection of ATP-induced nitric oxide in a biomimetic circulatory vessel containing an immobilized endothelium, Anal. Chem., 75 (2003) 145-151.

[24] K. Murakami, Y. Nakamura, Y. Yoneda, Potentiation by ATP of lipopolysaccharide-stimulated nitric oxide production in cultured astrocytes, Neuroscience, 117 (2003) 37-42.

[25] B. Sperlagh, G. Hasko, Z. Nemeth, E.S. Vizi, ATP released by LPS increases nitric oxide production in raw 264.7 macrophage cell line via P2Z/P2X7 receptors, Neurochem. Int., 33 (1998) 209-215.

[26] M.G. Espey, K.M. Miranda, R.M. Pluta, D.A. Wink, Nitrosative capacity of macrophages is dependent on nitric-oxide synthase induction signals, J. Biol. Chem., 275 (2000) 11341-11347.

[27] A. Tiscornia, E. Cairoli, M. Marquez, A. Denicola, O. Pritsch, A. Cayota, Use of diaminofluoresceins to detect and measure nitric oxide in low level generating human immune cells, J. Immunol. Methods, 342 (2009) 49-57.

[28] B.A. Wagner, S. Venkataraman, G.R. Buettner, The rate of oxygen utilization by cells, Free Radic. Biol. Med., 51 (2011) 700-712.

[29] A.M. Andrews, D. Jaron, D.G. Buerk, P.L. Kirby, K.A. Barbee, Direct, real-time measurement of shear stress-induced nitric oxide produced from endothelial cells in vitro, Nitric Oxide, 23 (2010) 335-342. [30] M.B. Harris, H. Ju, V.J. Venema, H. Liang, R. Zou, B.J. Michell, Z.P. Chen, B.E. Kemp, R.C. Venema, Reciprocal phosphorylation and regulation of endothelial nitric-oxide synthase in response to bradykinin stimulation, J. Biol. Chem., 276 (2001) 16587-16591. 
[31] A. Dardik, L. Chen, J. Frattini, H. Asada, F. Aziz, F.A. Kudo, B.E. Sumpio, Differential effects of orbital and laminar shear stress on endothelial cells, J. Vasc. Surg., 41 (2005) 869-880.

[32] M.M. Salek, P. Sattari, R.J. Martinuzzi, Analysis of fluid flow and wall shear stress patterns inside partially filled agitated culture well plates, Ann. Biomed. Eng., 40 (2012) 707-728.

[33] R.E. Berson, M.R. Purcell, M.K. Sharp, Computationally determined shear on cells grown in orbiting culture dishes, Adv. Exp. Med. Biol., 614 (2008) 189-198.

[34] J.M. Greve, A.S. Les, B.T. Tang, M.T. Draney Blomme, N.M. Wilson, R.L. Dalman, N.J. Pelc, C.A. Taylor, Allometric scaling of wall shear stress from mice to humans: quantification using cine phasecontrast MRI and computational fluid dynamics, Am J Physiol Heart Circ Physiol, 291 (2006) H1700-1708. 


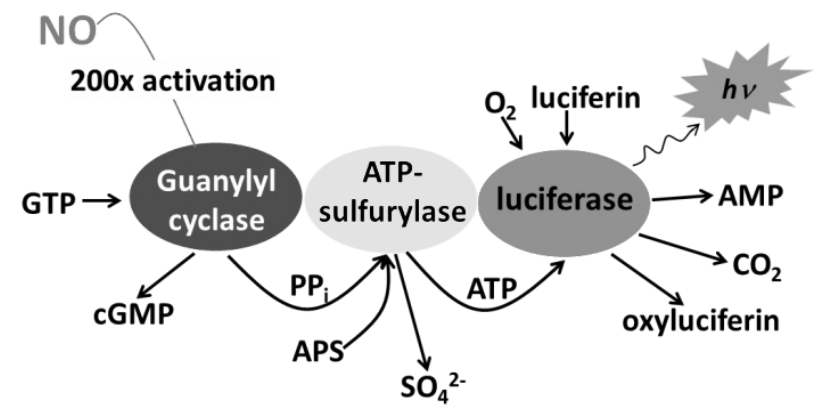

Scheme 1 

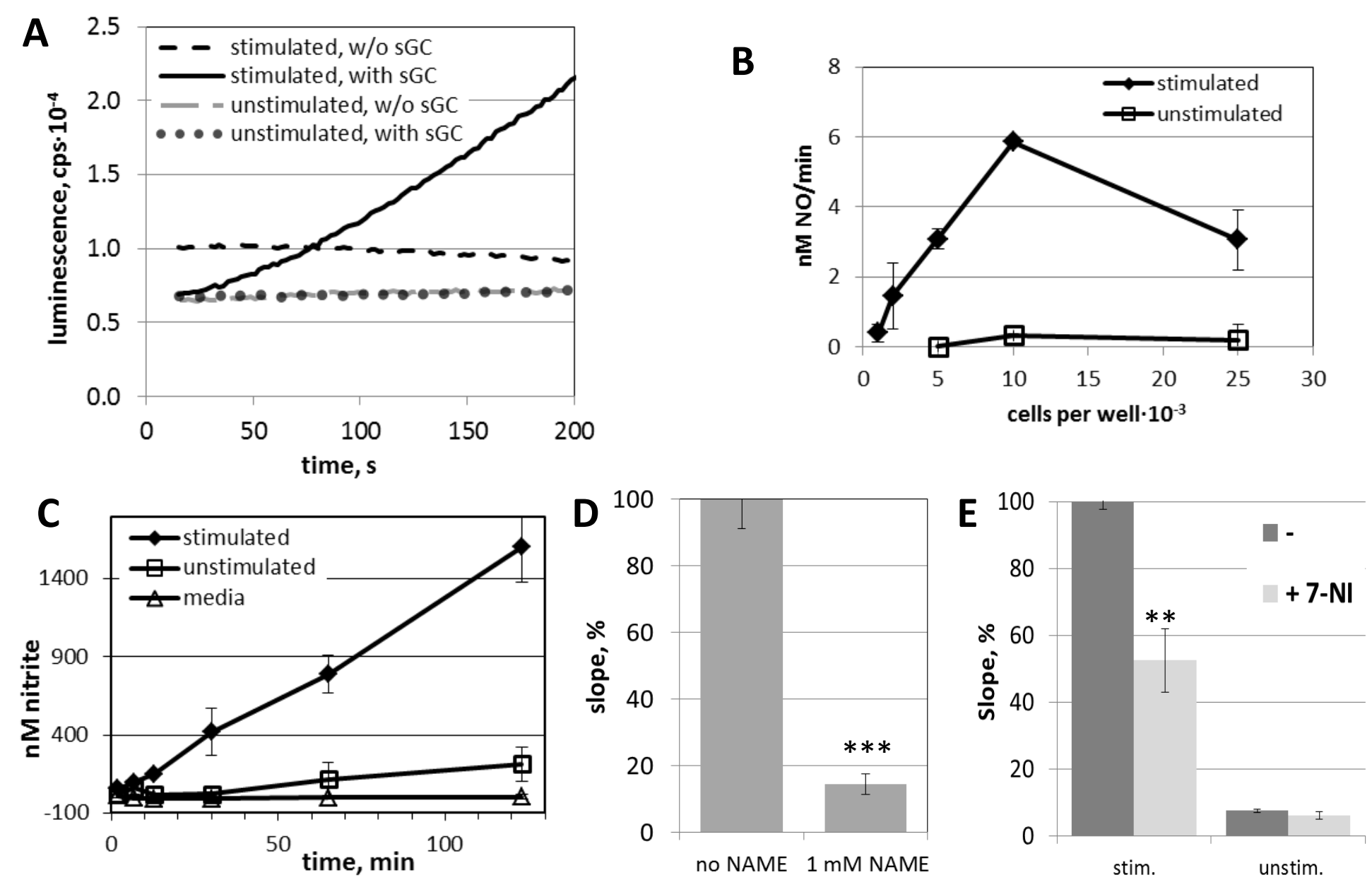

Figure 1 

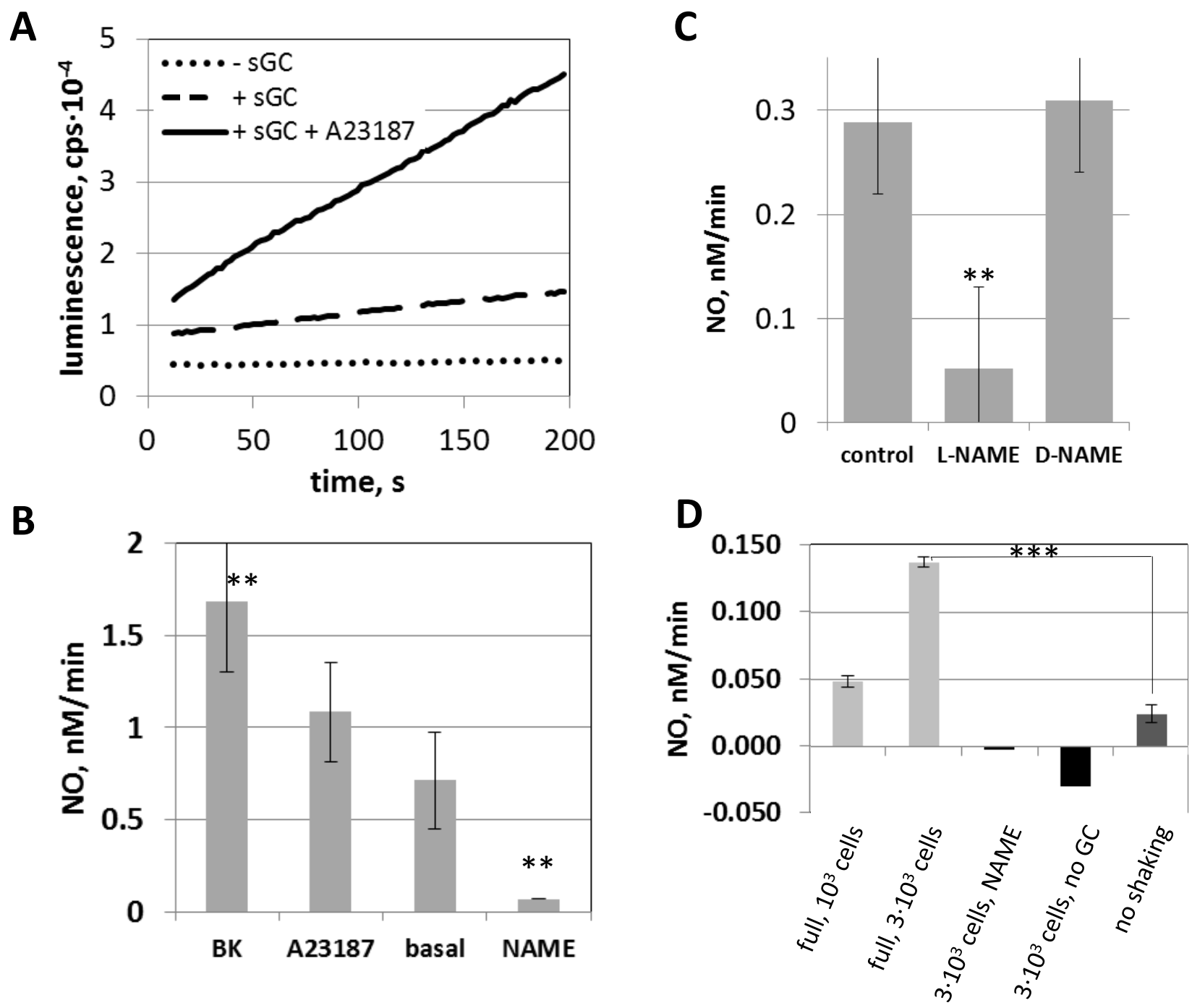

Figure 2 

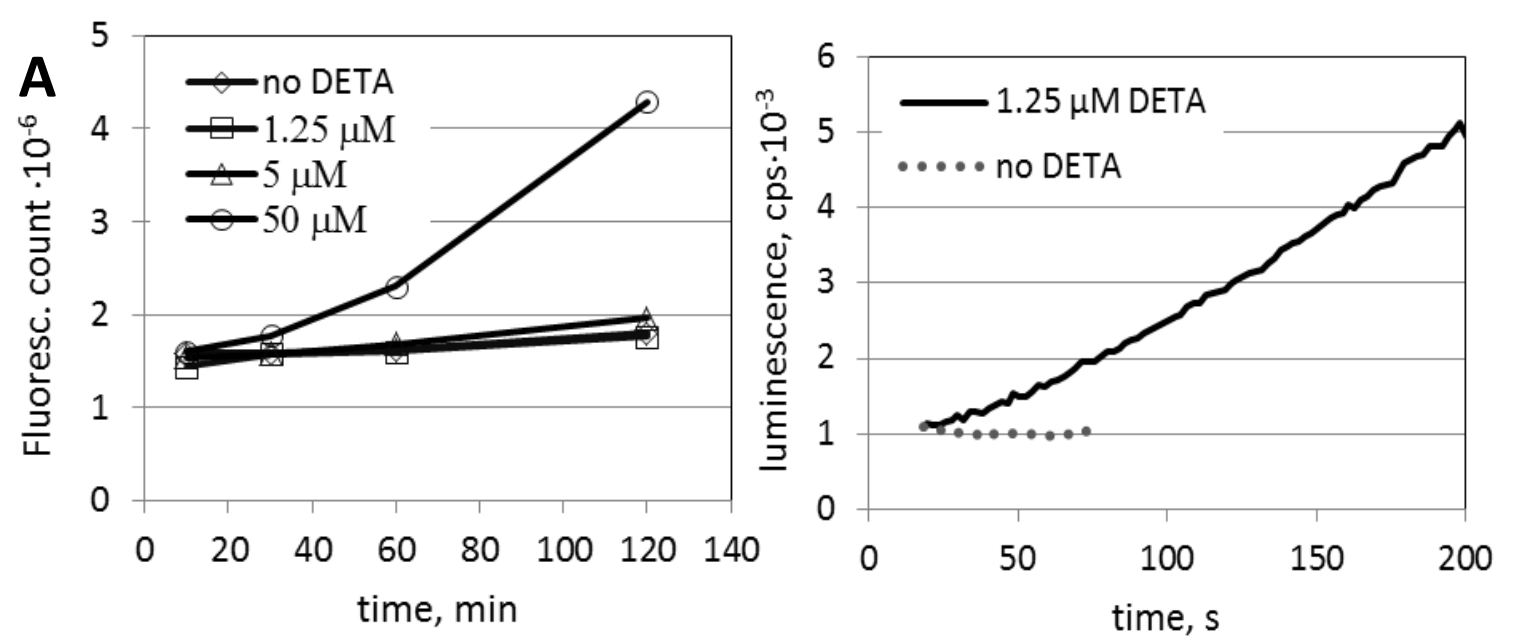

C
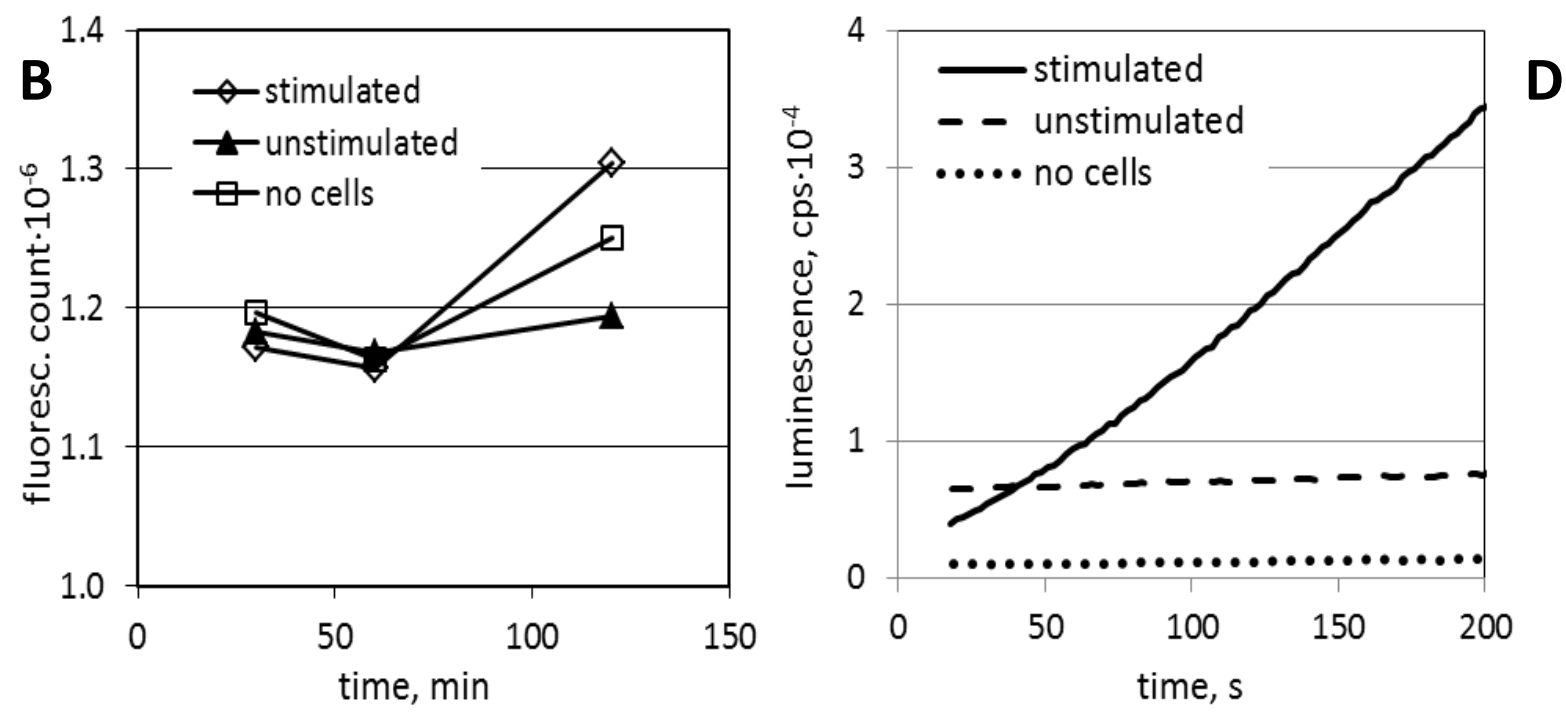

Fig. 3 


\section{Figures Captions}

Scheme 1. General outline of the chemiluminescence detection of nitric oxide. Soluble guanylyl cyclase converts GTP to cGMP and pyrophosphate $\left(\mathrm{PP}_{\mathrm{i}}\right)$ in reaction accelerated by NO. The product of the reaction, $\mathrm{PP}_{\mathrm{i}}$, is converted to ATP by ATP-sulfurylase. Finally, ATP causes the light emission centered at $560 \mathrm{~nm}$ in luciferase reaction.

Figure 1. NO generation by RAW 264.7 cells measured by luciferase chemiluminescence. Cells were stimulated by INF- $\gamma$ and LPS. The medium was replaced with $200 \mu \mathrm{L}$ of MP-HEPES prior to measurement. Two types of controls were used: reaction containing all the components except sGC and reaction containing unstimulated cells. A, individual kinetics, $1.0 \cdot 10^{3}$ cells per well. B, NO production, depending on the number of cells. C, Nitrite production by RAW cells $\left(2.5 \cdot 10^{4}\right.$ per well), fluorometric measurements; "media" means buffer without cells. D, Inhibition of NO production by L-NAME, added to the stimulated cells $\left(1.0 \cdot 10^{4}\right.$ per well) in standard growth medium 50 min prior to measurements. $\mathbf{E}$, Inhibition of NO production by 7-nitroindazole $(50 \mu \mathrm{M})$ added directly before measurement; $2.0 \cdot 10^{3}$ cells/well. Average of duplicates (B, C, E) or triplicate (D). ${ }^{* *} \mathrm{P}<0.05$, ${ }^{* *} P<0.005$, vs. no inhibitor.

Figure 2. NO generation by BAEC measured by luciferase chemiluminesce. After addition of the components of the assay and temperature stabilization, $\mathrm{Ca}^{2+}$ ionophore A23187 $(1 \mu \mathrm{M})$ or bradykinin $(10 \mu \mathrm{M})$, was added. Then, after $90 \mathrm{~s}$ delay, $\mathrm{Ca}^{2+}$ chelator (EGTA) and sGC were added and kinetic was recorded. For background measurement, sGC was omitted; for basal NO generation, buffer was added instead of stimulant. A, primary kinetic curves for background ($\mathrm{sGC})$, basal (+sGC) and $\mathrm{Ca}^{2+}$ - stimulated (+sGC+A23178) NO generation. B, rate of NO generation for bradykinin- or A23187-stimulated, basal and L-NAME-inhibited luminescence. L-NAME (1 mM) was added to growth medium $1 \mathrm{~h}$ prior to the measurements. Average of triplicates. $\mathbf{C}$, effect of $\mathrm{L}-$ and D-NAME, added 15 min prior to measurements, on NO generation. D, NO generation induced by mechanical stress (shaking). Cells were shaken directly in the plate reader immediately after addition of SGC. Shaking parameters are given in Materials and Methods. Measurements were conducted in Hi HEPES medium without $\mathrm{Ca}^{2+}$. Bars represent $1.0 \cdot 10^{3}$ and $3.0 \cdot 10^{3}$ cells with full NO detection system, 3.0.10 ${ }^{3}$ cells preincubated with L-NAME for $1 \mathrm{~h}, 3.0 \cdot 10^{3}$ cells with NO detection system missing SGC and $3.0 \cdot 10^{3}$ cells with full NO detection system without shaking. The last one is recalculated from the measurements made with $3.0 \cdot 10^{4}$ cells. ${ }^{*} P<0.05 \mathrm{vs}$. basal level, ${ }^{* * *} P<0.005$ vs. non-shaking.

Figure 3. Comparison of sensitivity for fluorescent NO indicator DAF-FM and SGC-luciferase chemiluminescence. Measurements were conducted in Hi HEPES using 96-well plates, with DETA NONOate or RAW cells as a source of NO. A, Different concentrations of DETA NONOate were added to the buffer containing DAF-FM $(10 \mu \mathrm{M})$ and incubated at $37^{\circ} \mathrm{C}$ in the dark for specified time. B, DAF-FM $(10 \mu \mathrm{M})$ was added to $1.0 \cdot 10^{4}$ RAW 264.7 cells stimulated as described or unstimulated. At a specified time, $150 \mu \mathrm{L}$ was withdrawn and fluorescence was measured with 485 $\mathrm{nm}$ excitation and $535 \mathrm{~nm}$ emission filters. C, DETA NONOate was added to the buffer containing all the components of sGC-luciferase assay. D, all the components of sGC-luciferase assay were added to the same cells as in B. Notice the different time scale on the panels. 


\section{Graphical Abstract}

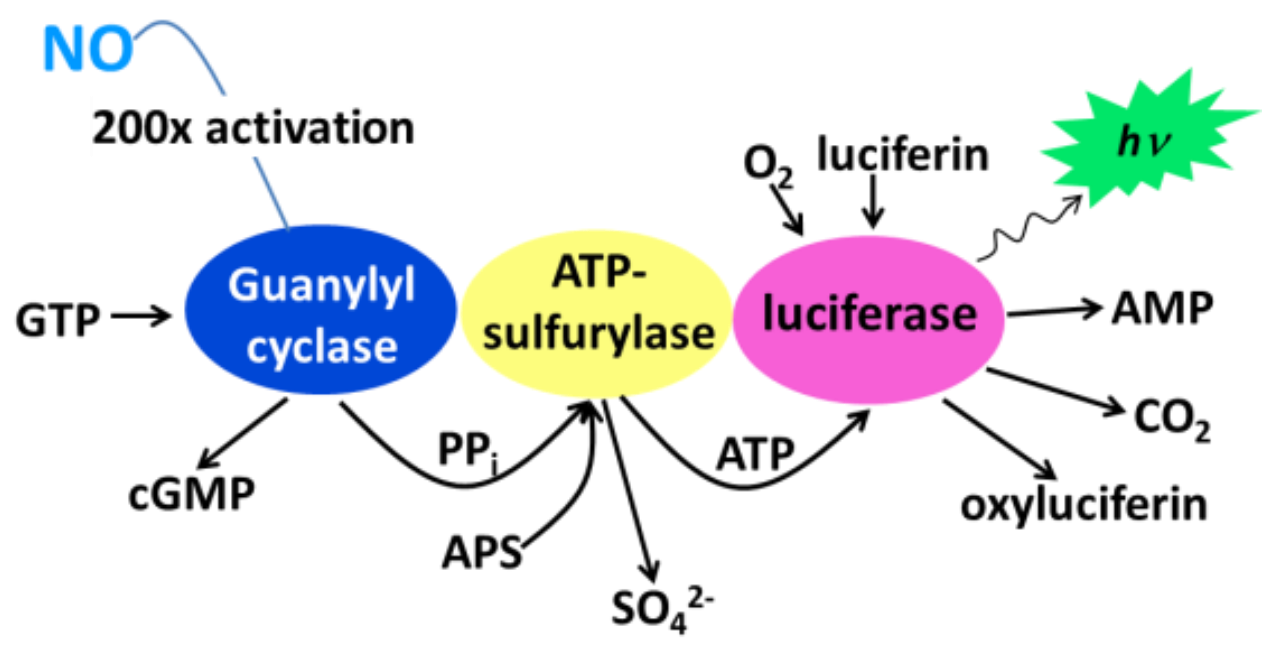

